\title{
"Ei, eu também estou aqui!": aspectos psicológicos da percepção de irmãos frente à presença de uma criança com paralisia cerebral no núcleo familiar
}

\author{
"Hey, I'm here too"!: the psychological aspects from \\ the point of view of the siblings of a child with \\ cerebral palsy in the family nucleus
}

\author{
Heloise de Bastos NAVARAUSCKAS \\ Íris Barreto SAMPAIO' \\ Marcela Pereira URBINI' \\ Regina Célia Villa COSTA
}

\begin{abstract}
Resumo
Este artigo tem por objetivo analisar o impacto do nascimento de uma criança com paralisia cerebral no núcleo familiar e a percepção dos irmãos frente à situação. Parte-se do pressuposto de que o irmão da criança com deficiência é bastante afetado com o nascimento desta e, frequentemente, pouco assistido. Utilizou-se entrevista semi-estruturada com pais e irmãos primogênitos de crianças especiais, tendo como parâmetro um grupo-controle com os mesmos critérios, sendo que neste a deficiência não estava presente. Foi observado prejuízo na relação pais-primogênitos, bem como precoce amadurecimento destes últimos, ocasionado pela necessidade de adaptação. Por fim, ressalta-se a importância de maior atenção ao irmão da criança especial.
\end{abstract}

Unitermos: Irmãos. Paralisia cerebral. Relações familiares

\begin{abstract}
This article analyses the impact of the birth of a child with cerebral palsy in the family, and the viewpoint of the siblings concerning this situation. The assumption is that the sibling of a child with a disability is significantly impacted, but that this is rarely recognized. Parents and older siblings of the special needs child were interviewed, having as a parameter a control group that observes the same criteria, but without a disabled child. There was found to be damage in the parent-firstborn relationship and a tendency for the older child to grow up more quickly, caused by her need to adapt. We would stress the need to pay greater attention to the siblings of special needs children.
\end{abstract}

Uniterms: Brothers. Cerebral palsy. Family relations.

\footnotetext{
UVR

1 Associação de Assistência à Criança Deficiente. Av. Prof. Ascendino Reis, 724, Vila Clementino, 04027-000, São Paulo, SP, Brasil. Correspondência para/Correspondence to: M. P. URBINI. E-mail: <marcela@marcela.urbini.psc.br>.
} 
Durante a gravidez, a família precisa passar por uma reestruturação, redefinindo seu funcionamento, modificando seus papéis, visando a uma melhor adaptação ao novo momento (Fiamenghi Jr. \& Messa, 2007; Pereira \& Piccinini, 2007).

Nessa fase, os futuros pais manifestam sentimentos de dúvida e ansiedade em relação ao desenvolvimento do bebê (Höher \& Wagner, 2006), já que a chegada de um filho muda a estrutura da família. Comumente, elaboram projetos, sonham com o crescimento da criança, fazem planos para ela (Madaleno \& Cristante, 2007). E com cada filho vem sempre a expectativa de um futuro promissor.

As relações familiares são as primeiras que a criança estabelece com o mundo que a cerca. É através da família que o bebê é alimentado, cuidado e estimulado. Assim, são os pais que favorecem a sobrevivência do bebê e se constituem como objeto de suas primeiras relações sociais (Ingberman \& Löhr, 2003). Além disso, a família influencia, através da relação que estabelece com seus membros, o desenvolvimento infantil (Nunes \& Aiello, 2008). Entretanto, essas relações não são estáticas, modificam-se constantemente, e isso é intensificado com a chegada de um novo integrante.

Essas crianças crescem e começam a perceber que desempenham um papel a mais. Além de filhos, são irmãos. Apontada como uma das relações mais intensas (Perez 1998; Silveira, 2001) e duradouras, a relação entre irmãos é composta por fases, que mudam de acordo com o desenvolvimento destes (Petean \& Suguihura, 2005).

Segundo Pereira e Piccinini, 2007, "o principal impacto da gestação do segundo filho parece recair sobre a família nuclear, envolvendo a relação conjugal, o relacionamento pais-primogênito e, em particular, o primogênito". interdependentes, e não apenas uma junção de seus membros, pois quando um elemento é modificado os outros sofrem consequências (Pratta \& Santos, 2007).

O nascimento de um irmão faz que essa família necessite de "ajustes". Atenções e cuidados são disputados diariamente. Para Petean e Suguihura (2005), com o nascimento do segundo filho, a estrutura e a dinâmica familiar são modificadas. O irmão mais velho tem que se adaptar ao mais novo, dividindo espaço físico, atenção e dedicação dos pais, o que pode gerar sentimentos de ciúme e raiva.

Essas modificações podem ser ainda mais intensas se o filho recém-nascido tiver alguma limitação. Isso acontece porque "o impacto sentido pela família com a chegada de uma criança com algum tipo de deficiência é intenso" (Dessen \& Silva, 2001, p.136), já que as expectativas que os pais tinham acerca de um bebê "perfeito" são frustradas, e eles são levados a se adaptar ao bebê real. São necessários reajustes psicossociais que estimulem a melhoria da qualidade de vida da criança e da família como um todo (Freitas, Carvalho, Leite \& Haase, 2005).

A família que tem uma criança sem deficiência tem nela um parâmetro de comparação para o segundo filho. Considerando-se as limitações do bebê com deficiência, os pais têm que cuidar para que o relacionamento com ele seja o mais próximo possível do modo como se relacionam com seu irmão, estando atentos para não exigir mais do que a criança possa fazer (Schmidt, 2003).

Os irmãos também sofrem o impacto do nascimento de uma criança com deficiência. Petean e Suguihura (2005) relatam que eles precisam lidar com a frustração do sonho do irmão perfeito. Assim como os pais, necessitam elaborar a aceitação do irmão. Deverão aprender a conviver com as questões sociais, as dificuldades de entendimento do diagnóstico e a ambiguidade de sentimentos para com ele, podendo ter seu desenvolvimento e cotidiano influenciados (Matsukura \& Cid, 2004).

Para Ardore, Hoffman e Regen (1988), o irmão de uma criança com desenvolvimento atípico pode apresentar diversos sentimentos e reações frente à nova situação. Pode demonstrar ciúme, inveja, superproteção, orgulho, culpa, vergonha, tristeza, preocupação, solidão, negação ou até mesmo dificuldade de relacionamento com os amigos.

Frente à necessidade de se adaptarem ao filho com deficiência e de atenderem aos cuidados que ele exige, os pais frequentemente mudam o relacionamento que tinham com os outros filhos que:

Por vezes, são negligenciados; podendo ser exercida sobre eles maior pressão para que 'brilhem' na 
vida, compensando assim o possível 'fracasso' do irmão deficiente. Poderão sentir-se culpados pela deficiência do irmão, enciumados ou em desvantagem, por acreditarem que o irmão deficiente goza de privilégios e excesso de atenção dos pais (Ferrareto \& Souza, 1998).

O modo como esses irmãos irão acolher o bebê está ligado ao modelo apresentado por seus pais. Rejeição ou aceitação serão reflexos da relação observada (Ferrareto \& Souza, 1998).

Equilibrar essa dinâmica é tarefa difícil para os pais, especialmente para a mãe, que, na maioria das vezes, é a principal cuidadora (Madaleno \& Cristante, 2007; Souza \& Pires, 2003). Ao mesmo tempo em que precisam lidar com a perda do filho imaginado e assistir aquele bebê que demanda cuidado especial, também precisam conseguir conciliar as tarefas para com o outro filho, tendo que ampará-lo em suas necessidades e dar o carinho e apoio de que antes ele dispunha.

Os filhos exigem atenção, cada um com sua especificidade. Os irmãos não buscam diferenças, focam o mesmo objeto: os pais. Essa relação deve ser cuidadosamente elaborada, para que se tornem parceiros e possam desenvolver um relacionamento harmônico. Como explicam Fiamenghi e Messa (2007), ter um irmão deficiente não é em si uma situação geradora de problemas, dado que as relações entre os irmãos dependerão, entre outros aspectos, da estrutura familiar e do modo como essa família lida com a deficiência.

Os pais podem procurar o auxílio da Psicologia para favorecer a adaptação à nova realidade, buscando estratégias de enfrentamento para as necessidades e expectativas emergentes, considerando o contexto de suas relações sociais (Araújo, 2004).

Frente à necessidade observada, e com embasamento da revisão bibliográfica, percebe-se a importância de pesquisas que enfoquem a relação da criança com o irmão deficiente.

É notório que há estudos que analisam a relação dos pais com seus filhos especiais, mas o sentimento dos irmãos raramente é abordado (Matsukura \& Cid, 2004); Bosa \& Gomes (2004). O estudo torna-se ainda mais importante quando se percebe que parte das instituições que atendem crianças com deficiência não tem um atendimento específico aos irmãos. Na instituição em que a pesquisa foi realizada, estudava-se a possibilidade de atendê-los, entretanto sem saber ao certo se esse trabalho seria necessário.

Percebida essa situação, optou-se por desenvolver uma pesquisa na qual pudessem ser estudados os aspectos psicológicos dos irmãos de portadores de paralisia cerebral - doença conceituada como "um grupo de desordens com comprometimento motor, não progressivas, mas sujeitas a mudanças, secundárias a lesões ou anomalias do cérebro, que originam nos estágios precoces de seu desenvolvimento" (Baladi, Castro \& Morais Filho, 2007), bem como o impacto de uma criança deficiente no núcleo familiar.

\section{Método}

O presente estudo foi desenvolvido no setor de Psicologia de um Centro de Reabilitação de São Paulo, no período de junho a setembro de 2008, sob abordagem qualitativa. O centro de reabilitação em questão é uma entidade privada, sem fins lucrativos, que atende pessoas de todas as classes socioeconômicas.

A casuística em estudo constituiu-se de 32 crianças e jovens de classe social média baixa a partir de oito anos, e seus pais. Entre os filhos, 16 eram irmãos mais velhos de crianças com paralisia cerebral, constituindo o Grupo de Estudo (GE), e os outros 16 eram irmãos mais velhos de crianças sem qualquer necessidade especial, compondo o Grupo-Controle (GC).

Os critérios de inclusão para a escolha da amostra do grupo de estudo foram: ser irmão ou irmã mais velho de criança com deficiência; ter idade igual ou superior a 8 anos; ter irmão em tratamento de reabilitação na clínica de paralisia cerebral da referida instituição no período da coleta de dados; morar junto com o irmão desde o nascimento deste. É importante salientar que parte das crianças entrevistadas tinha outros irmãos além da criança com deficiência, sendo critério para inclusão na pesquisa apenas a exigência de ser irmão primogênito de criança com paralisia cerebral. 0 grupo-controle foi escolhido respeitando as mesmas características etárias, socioeconômicas e culturais do grupo de estudo. A idade dos irmãos variou de 8 a 20 anos, com média de 10 anos e 4 meses. 
A participação dos primogênitos e pais foi vinculada ao consentimento verbal e escrito de ambos. No período da coleta de dados, todos os cuidadores que atenderam aos critérios da seleção foram incluídos na investigação. O trabalho foi submetido ao Comitê de Ética em Pesquisa da Associação da Assistência à Criança Deficiente (AACD) e aprovado sob protocolo n०016/2008.

Utilizou-se, como instrumento, entrevista semiestruturada direcionada aos primogênitos e seus pais (Quadro 1). O método de entrevista foi escolhido por exigir a presença do pesquisador para sua aplicação, favorecendo a busca de informações importantes para responder ao problema e esclarecer possíveis dúvidas (Gianfaldoni \& Moroz, 2002).

Os objetivos da pesquisa foram explicados para os pais e primogênitos participantes. Aqueles que aceitaram participar assinaram um termo de consentimento livre e esclarecido.

As respostas dos participantes foram analisadas e categorizadas de acordo com seu conteúdo. Os resultados foram avaliados qualitativamente, a partir de levantamento bibliográfico previamente realizado. Não foram observadas variáveis como escolaridade, classe social, gênero e cor.

Quadro 1. Modelo das entrevistas realizadas com pais e irmãos do grupo de estudo e grupo-controle.

Prupo de estudo

- Ao receber a notícia de que seu filho tinha paralisia cerebral como você reagiu?

- Você contou para seu outro filho sobre a deficiência do irmão? Como foi?

- Como você acha que seu filho reagiu à notícia?

- Como você classificaria a relação de seus filhos?

- O que você espera de seu filho em relação ao irmão com paralisia cerebral?

- Você considera que sua relação com seu filho mudou depois do nascimento do irmão? Se sim, em que aspecto?

- Você considera que seu filho teve algum prejuízo após o nascimento do irmão?

- Você considera que seu filho teve algum ganho após o nascimento do irmão?

- Em que aspectos você considera que a deficiência de seu filho mudou a estrutura de sua família?
- Quando você soube que seu irmão tinha uma deficiência?

- O que você sentiu quando recebeu essa notícia?

- O que você sabe dizer a respeito do diagnóstico de seu irmão?

- Alguma coisa mudou na sua família com o nascimento de seu irmão? Se sim, o que?

- A sua relação com seus pais mudou depois que seu irmão nasceu? Se sim, como?

- Você tem alguma responsabilidade para com o seu irmão?

- O que mudou na sua vida depois que seu irmão nasceu?

- O que você acha de ter um irmão especial?

- Você tem alguma preocupação em relação ao seu irmão?

\begin{tabular}{cl}
\hline & Grupo-Controle \\
\hline Pais & Irmãos \\
\hline
\end{tabular}

- Como você classificaria a relação de seus filhos?

- O que você espera de seu filho em relação ao irmão?

- Você considera que sua relação com seu filho mudou depois do nascimento do irmão? Se sim, em que aspecto?

- Você considera que seu filho teve algum prejuízo após o nascimento do irmão?

- Você considera que seu filho teve algum ganho após o nascimento do irmão?

- Em que aspectos você considera que o nascimento de seu segundo filho mudou a estrutura de sua família?
- Alguma coisa mudou na sua família com o nascimento de seu irmão? Se sim, o que?

- A sua relação com seus pais mudou depois que seu irmão nasceu? Se sim, como?

- Você tem alguma responsabilidade para com o seu irmão?

- O que mudou na sua vida depois que seu irmão nasceu?

- O que você acha de ter um irmão? ...

- Você tem alguma preocupação em relação ao seu irmão? 


\section{Resultados}

A partir do levantamento de dados, foi possível perceber que frente à notícia 38,8\% dos pais reagiram com choque, $22,2 \%$ com tristeza, $11,1 \%$ com desespero, 11,1\% negaram a situação, 5,5\% disseram-se revoltados, 5,5\% rejeitaram a criança e 5,5\% sentiram-se autocobrados.

Todos os irmãos entrevistados foram, segundo seus pais, informados em relação à deficiência do novo familiar, sendo que apenas um pai referiu aguardar o filho questionar sobre esse aspecto para transmitir a informação. A estratégia dos pais, em relação ao relato da notícia, foi explicar sobre aspectos referentes à limitação física $(40,0 \%)$ ou inserir o filho ativamente na dinâmica familiar, favorecendo sua percepção (26,6\%). $O$ restante dos pais entrevistados apenas informou 0 primogênito sem definir qualquer estratégia (33,3\%).

Ao serem questionados sobre como perceberam a reação do primogênito, 37,5\% dos pais afirmaram que ele ficou triste, 31,2\% não perceberam qualquer reação diferente, $12,5 \%$ relataram choque, 6,2\% observaram superproteção para com o irmão, 6,2\% reagiram sob forma de negação e 6,2\% acharam que o filho não entendeu o que estava sendo dito. Já os irmãos, quando questionados sobre sua reação, referiram tristeza em $42,1 \%$ dos casos, choque em $21,0 \%$, conformismo em 10,5\%, abalo e agonia em 10,5\% e 15,8\% referiram ausência de reação, por desconhecerem o quadro clínico.

A desinformação foi algo presente quando se abordou o diagnóstico da criança especial: $37,5 \%$ dos primogênitos definiram a deficiência com base em aspectos visíveis (dificuldade motora), 12,5\% citaram um atraso no desenvolvimento e 50,0\% não conseguiram fornecer nenhuma informação sobre o assunto.

A respeito da dinâmica familiar após o nascimento do irmão portador de deficiência 25,0\% dos primogênitos disseram que nada mudou; $18,7 \%$, que aumentaram os conflitos em casa; $18,7 \%$, que diminuíram os conflitos; $12,5 \%$, que a família ficou mais unida; 12,5\% sentiram-se excluídos; 6,2\% relacionaram à inserção de mais uma pessoa na família e 6,2\%, que a família ficou menos unida. Já no grupo-controle, 43,7\% dos irmãos entrevistados não relataram mudança na dinâmica familiar. Dos que perceberam alteração, 25,0\% fizeram referência à união familiar, 12,5\% referiram aumento ou diminuição de conflitos, 12,5\% observaram maior agitação no dia a dia e 6,2\% demonstraram ciúme.

Quanto ao relacionamento entre o primogênito e o irmão portador de paralisia cerebral, os pais o classificaram como uma relação de amizade em $81,2 \%$ dos casos, e de grande frequência de brigas em 18,7\%. Esse número foi semelhante no grupo-controle, no qual 93,7\% dos pais consideraram que seus filhos possuem um relacionamento amigável e 6,2\% apontaram que o relacionamento é distante em função da diferença de idade.

Quanto a mudanças na relação pai-filho após o nascimento da criança especial, 56,2\% dos primogênitos não perceberam alteração na interação com os pais, enquanto 43,7\% disseram ter havido mudança. Destes, 75,0\% referiram prejuízo na atenção, 12,5\% relataram constantes faltas escolares em decorrência do tratamento do irmão e 12,5\% narraram desorganização da rotina. No grupo-controle, frente ao nascimento de irmão sem qualquer necessidade especial, 37,5\% dos primogênitos referiram mudança no relacionamento com os pais, 50,0\% não perceberam alteração e 12,5\% referiram não lembrar. Entre aqueles que relataram mudanças, 66,6\% perceberam atenção reduzida após o nascimento, enquanto $16,6 \%$ relataram que seus pais ficaram mais alegres e 16,6\% referiram maior união entre eles e os pais da família.

Dos pais de criança com paralisia cerebral, apenas 31,2\% não perceberam que a relação com o primogênito foi modificada. Entre os que afirmaram mudança, 45,4\% notaram atenção reduzida, 36,3\% referiram alteração na dinâmica familiar e 18,2\% relataram que a família ficou mais unida. No grupo-controle os resultados foram semelhantes.

Ao serem questionados sobre possíveis prejuízos ao primogênito em decorrência do nascimento do mais novo, 50,0\% dos pais do grupo de estudo afirmaram não tê-lo havido. Dos que avaliaram alguma perda, $62,5 \%$ referiram atenção reduzida; $25,0 \%$, prejuízo escolar; $12,5 \%$, dificuldade em relação ao aspecto financeiro (ressaltando despesas com medicamentos, transportes etc.). No grupo utilizado como parâmetro, apenas $18,7 \%$ dos pais notaram algum prejuízo, dos quais $66,6 \%$ fizeram referiram maior dificuldade financeira e 33,3\% relataram que os avós diminuíram a atenção para com o primeiro neto. 
Com relação aos ganhos obtidos, 18,7\% afirmaram não ter percebido qualquer tipo. Dos $81,2 \%$ restantes, $71,4 \%$ relataram maior maturidade/responsabilidade, 14,3\% classificaram como ganho a chegada de um novo membro na família, 7,1\% relacionaram ganhos mate-riais e $7,1 \%$ maior liberdade. No grupo- controle, $81,2 \%$ dos pais perceberam ganhos após o nascimento do irmão, sendo que 75,0\% mencionaram que o primogênito ganhou uma companhia, 16,6\% referiram ganhos materiais e 8,3\% aumento na maturidade.

A maioria dos pais entrevistados percebeu que a deficiência do filho alterou a estrutura da família $(89,4 \%)$. Foram considerados os seguintes aspectos: mudança na rotina (47,0\%), desequilíbrio psicológico (23,5\%), aumento da união familiar (23,5\%) e aumento da responsabilidade (5,8\%). No grupo-controle, 37,5\% dos pais entrevistados não referiram alteração na estrutura familiar após o nascimento do segundo filho, 37,5\% mencionaram desestruturação da rotina, 18,7\% relataram dificuldades financeiras e 6,2\% que o filho mais velho aprendeu a compartilhar.

Todos os irmãos entrevistados revelaram ter algum tipo de responsabilidade em relação à criança deficiente: 65,0\% auxiliam nos cuidados diários, 20,0\% têm participação ativa no processo de reabilitação e 15,0\% estimulam atividades de lazer. No grupo-controle, 75,0\% afirmaram ter alguma responsabilidade em relação ao irmão mais novo, sendo esta direcionada a alguma atividade lúdica.

Quando questionados sobre ter um irmão especial, 25,0\% dos entrevistados relataram contentamento; 23,5\% demonstraram necessidade de aceitar tal situação; $23,5 \%$, descontentamento; $17,6 \%$ negaram a questão da deficiência; 35,2\% preferiram não responder. Já no grupo usado como parâmetro, quando questionados sobre ter um irmão, relataram contentamento em $81,25 \%$ das vezes, enquanto que $18,7 \%$ demonstraram incômodo nas situações de briga.

Dos irmãos entrevistados, 56,2\% mencionaram preocupação com a criança especial, enquanto 43,7\% não referiram preocupação, sendo que destes 14,2\% não a relataram por haver uma expectativa de cura. Dos que se relataram preocupação, 44,4\% temem as limitações impostas pela deficiência; 33,3\%, as complicações clínicas; $11,1 \%$, a dificuldade no convívio social e 11,1\% refe- rem medo em relação ao futuro. A preocupação no grupo de crianças sem necessidade especial apareceu em 68,7\% dos casos nos seguintes aspectos: receio de ferimentos $(57,1 \%)$, de doença $(21,4 \%)$, de sequestro $(14,2 \%)$ e de incapacidade de cuidado $(7,1 \%)$.

\section{Discussão}

O nascimento de uma criança com necessidades especiais é impactante para toda a família. Com base nos resultados expostos pôde-se perceber que, ao serem informados acerca da deficiência do irmão, a maioria dos entrevistados $(84,2 \%)$ teve uma reação negativa, como tristeza, choque, negação etc., enquanto o restante não manifestou reação por desconhecer o quadro clínico. As experiências compartilhadas entre os irmãos são as primeiras e mais intensas que uma pessoa divide com outra, já que essas relações se estabelecem em um mesmo nível hierárquico (Falke, Silveira \& Masmann, 2002).

A deficiência desnivela o relacionamento, o irmão mais velho "perde" o irmão idealizado, podendo, dessa forma, justificar o negativismo em suas reações. Entretanto, nesse momento, poucos demonstraram ter conhecimento sobre o diagnóstico, favorecendo crenças e fantasias a respeito, como pode ser visto no seguinte depoimento: "...eu sei que ela pode ser curada com os tratamentos"(11 anos).

Mediante os relatos dos entrevistados pôde-se notar que a maioria dos irmãos (75\%) de crianças especiais sofreu o impacto do nascimento da criança com paralisia cerebral, apontando alterações na estrutura familiar. "Mudou muito. Agora é mais cuidado com ele, a gente só saípro hospital e pra lgreja, quando ele tá bom a gente sai" (10 anos).

A mudança percebida na estrutura da família, pelo grupo-controle, foi bastante diferente, apontando para fatos como intensificação da rotina e união familiar. Nos depoimentos aparecem questões sobre o brincare a alegria, diferindo do outro grupo, que trouxe questões de pesar e tristeza. Apesar disso, o relacionamento dos irmãos foi percebido pelos pais como amigável na maioria dos casos (81,2\% GE e 93,7\% GC), em ambos os grupos. 
Quando um novo membro é integrado à família há a necessidade de reorganização por parte desta (Pereira \& Piccinini, 2007). A maioria dos pais entrevistados no grupo de estudo $(68,6 \%)$ referiu mudança na interação com o filho mais velho.

"Perdi a paciência com ela. Ela quer aproveitar que eu tenho a menina pra cuidar e quer vazar. Antes a gente era muito mais amiga, ela me trocou pelas amigas da escola e eu a troquei pela B" (mãe GE).

Esse relato denota a exaustão da mãe frente aos cuidados exigidos pela criança com deficiência. O cuidador, que em geral são as mães, sofre diretamente as complicações psicológicas da presença de uma criança com paralisia cerebral (Freitas et al., 2005). Esse abalo é refletido na relação com os outros filhos, que são afetados e percebem essa alteração, como no exemplo: "Eles dão mais atenção para ele, claro... quem não ia dar mais atenção para o deficiente? Eu falto mais na escola pra trazer ele, ajudar a carregar a sacola, porque a minha mãe tem varizes" (10 anos).

A deficiência ressalta a necessidade de se compartilhar a atenção, o que já é esperado quando do nascimento de outra criança, e intensificado quando ela é especial. O primeiro filho sofre esse impacto de maneira gritante, o que interfere em diversos aspectos de seu desenvolvimento. O grupo-controle traz essa alteração de outra maneira, apontando mudança na atenção que precisa ser dividida em função de haver outra criança no lar.

Metade dos pais do grupo de estudo percebeu prejuízos para o filho mais velho, justificando-os pela atenção necessária ao filho com deficiência. "Ela não se interessava muito pelos estudos, dava muito trabalho na escola, levei ela no médico que passou uma vitamina. Foi depois que ele nasceu, acho que ela se sentiu meio só" (mãe $\mathrm{GE})$.

Já os pais de crianças sem qualquer necessidade especial não perceberam, em sua maioria $(81,2 \%)$, perdas para o filho mais velho. Com relação aos ganhos, esses pais fizeram referência à companhia, enquanto no grupo de estudo os ganhos observados foram bastante divergentes. Os pais de crianças especiais referiram aumento na maturidade/responsabilidade do primogênito, percebendo-a como ponto positivo, e não como prejuízo para o desenvolvimento, o que ilustra a necessi- dade de o irmão se ajustar à nova situação, que exige compreensão e cuidados diários. "Acho que ficou mais consciente das coisas, mais real. Antes era muito iludido, ficou mais adulto. Ele quer saber como faz a fisio, como é prafazer em casa pra ele ajudar" (mãe GE).

Ao fazer referência à "ilusão" da criança, a mãe valoriza o rápido crescimento do filho, em detrimento da fantasia infantil, necessária ao desenvolvimento emocional saudável.

A exigência dessa maturidade pode ser demonstrada frente à percepção dos irmãos quanto a sua responsabilidade com a criança especial, o que apareceu em $100 \%$ dos casos no grupo de estudo. "Comida meu irmão dá, eu dou banho e olho ele de sábado e domingo, porque minha mãe trabalha" (12 anos).

O depoimento traduz a responsabilidade da criança na realização de tarefas importantes para a sobrevivência do irmão mais novo. Grande parte dos primogênitos do grupo usado como parâmetro $(75,0 \%)$ também relatou alguma responsabilidade em relação ao caçula, o que, entretanto, apareceu mais como um comportamento espontâneo seu do que como uma necessidade da família. "Quando ele tá brincando na rua eu grito: - V., olha o carro!" (10 anos).

Apesar do enfoque diferenciado, os primogênitos dos dois grupos demonstraram preocupação pelo irmão mais novo, fato característico na maioria das relações fraternais. Essa responsabilidade pode estar vinculada ao desejo de "ganhar um irmão", que geralmente é manifestado pelas crianças. No grupo-controle, a maior parte delas $(81,2 \%)$ relatou alegria pelo desejo realizado. Quando esse irmão nasce com alguma limitação, a visão do primogênito frente ao relacionamento fraterno muda, seja através de aceitação (23,5\%), ou até mesmo de descontentamento (23,5\%), como pode ser ilustrado, respectivamente, nos depoimentos a seguir: "Quando converso com a minha mãe, assim... falo que acho que Deus escolheu a familia certa pra ele vim, porque todo mundo aceitou ele" (13 anos). "Nãoérejeitando ele, masé muito ruim. Quando eu crescervou sentirvergonhaporque ele não vaisaber o que táfazendo, com 20 anos vaiter idade de $10^{\prime \prime}(10$ anos).

A literatura enfatiza a necessidade de adaptação para favorecer o convívio, e a forma como isso acontecerá depende dos aspectos socioculturais da família e 
do modo como se dá a relação dos pais com a criança especial. Os mecanismos de enfrentamento que os irmãos irão utilizar dependem das relações pré-estabelecidas com o ambiente. Os modelos apresentados pelos pais influenciam essas reações.

A maioria das crianças $(81,2 \%)$ demonstra preocupação com o irmão especial, o que pode ser traduzido como uma demonstração de carinho e afeto. Essa preocupação se apresenta, principalmente, por fatos que concernem à própria deficiência e às complicações dela advindas. "Ah eu tenho, sabe por quê? Ele já morreu duas vezes, voltou por milagre de Deus, tenho medo que morra de novo" (12 anos).

Os irmãos de crianças sem qualquer necessidade especial referem preocupações com fatos cotidianos, como a violência da sociedade ou possíveis acidentes. "Dele se machucar, de ser eletrocutado, assim, fico sempre perto dele" (11 anos).

Comparando esses depoimentos, é interessante notar que a preocupação do irmão da criança com desenvolvimento atípico denota medo de uma complicação clínica, que já ocorreu e poderá voltar a acontecer, configurando-se como uma ameaça real. Já o irmão da criança com desenvolvimento típico demonstra uma preocupação mais idealizada, o que é comum no imaginário infantil, e interrompido no irmão da criança especial. Essa situação se torna alarmante, na medida em que os pais percebem o amadurecimento como evolução. Apesar disso, em última análise, a angústia dos irmãos dos dois grupos denota o medo da perda.

A presença de pessoa com deficiência no núcleo familiar é impactante para todos os integrantes. Pôde-se perceber que o irmão de uma criança com paralisia cerebral é diretamente afetado pela necessidade de reestruturação da dinâmica familiar, cujo foco passa a ser a criança com deficiência. Suas queixas pouco são assistidas, visto que a deficiência do outro demanda atenção e cuidados frequentes.

O irmão precisa adaptar-se à nova situação, e essa necessidade faz que ele amadureça mais rápido, pulando etapas do desenvolvimento global.

Observou-se que o relacionamento com os pais foi prejudicado, em função das exigências do irmão com deficiência. Sabendo que os pais são modelos para o crescimento, esse prejuízo pode ser estendido à relação fraternal. Visando a favorecer a estrutura da família, é importante o investimento, por parte dos profissionais da saúde, em pesquisas e intervenções que auxiliem os pais a melhor administrarem essa relação. Nesse sentido, a presente pesquisa colaborou para o trabalho da instituição em que foi realizada, na medida em que possibilitou a formulação de propostas para atender os irmãos das crianças nela tratadas.

\section{Referências}

Araújo, D. A. (2004). Psicologia no atendimento a crianças com paralisia cerebral. In C. L. F. A. Lima \& L. F. Fonseca. Paralisia cerebral: neurologia, ortopedia e reabilitação. Rio de Janeiro: Guanabara Koogan.

Ardore, M., Hoffmann, V. M. B., \& Regen, M. (1988). Eu tenho um irmão deficiente... Vamos conversar sobreisto? São Paulo: Edições Paulinas.

Baladi, A. B. Castro, N. M. D., \& Morais Filho, M. C. (2007). Paralisia cerebral. In A. C. Fernandes, A. C. R. Ramos, M. E. P. Casalis \& S. K. Hebert. Medicina e reabilitação: princípios e práticas (pp.15-34) ). São Paulo: Artes Médicas.

Bosa, C., \& Gomes, V. F. (2004). Estresse e relações familiares na perspectiva de irmãos de indivíduos com transtornos globais do desenvolvimento. Estudos de Psicologia, 9 (3), 533-561.

Dessen, M. A., Silva, N. L. P. (2001) Deficiência mental e família: implicações para o desenvolvimento da criança. Universidade de Brasília. Psicologia: Teoria e Pesquisa, 17 (2), 133-141.

Falke, D., Silveira L. M. B. O., \& Mosmann, C. P. (2002). A comunicação de famílias com filhos adolescentes. Psicologia em Estudo, 7 (1), 75-80.

Ferrareto, I., \& Souza, A.M.C. (1998). Paralisia cerebral:aspectos práticos. São Paulo: Frôntis Editorial.

Fiamenghi Jr., G. A., \& Messa, A. A. (2007). Pais, filhos e deficiência: estudo sobre as relações familiares. Psicologia Ciência e Profissão, 27 (2), 236-245.

Freitas, P. M., Carvalho, R. C. L., Leite, M. R. S. D. T., \& Haase, V. G. (2005). Relação entre estresse materno e inclusão escolar de crianças com paralisia cerebral. Arquivos Brasileiros de Psicologia, 57 (1). Recuperado em novembro, 2008, disponível em http://seer.psicologia.ufrj.br

Gianfaldoni, M. H. T. A., \& Moroz, M. (2002). O processo de pesquisa: iniciação. Brasília: Plano editora.

Ingberman, Y. K., \& Löhr, S. S. (2003) Pais e filhos: compartilhando e expressando sentimentos. In F. C. Conte \& M. Z. S. Brandão. Falo ou não falo? Expressando sentimentos e comunicando idéias (pp. 85-93). Arapongas: Mascenas.

Höher, S. P., \& Wagner, A. D. L. (2006). A transmissão do diagnóstico e de orientações a pais de crianças com 
necessidades especiais: a questão da formação profissional. Estudos de Psicologia (Campinas), 23 (2), 113-125. doi: 10.1590/S103-166X2006000200002.

Madaleno, I. M. P., \& Cristante, A. R. L. (2007). Relação entre equipe, criança e família. In J. M. A. Greve (Org.), Tratado de medicina de reabilitação. São Paulo: Rocca.

Matsukura, T. S., \& Cid, M. F. P. (2004). Conhecendo a realidade de irmãos mais velhos de crianças que possuem necessidades especiais. Revista Brasileira de Educação Especial, 10 (3), 355-370.

Nunes, C. C., \& Aiello, A. L. R. (2008). Interação entre irmãos: deficiência mental, idade e apoio social da família. Psicologia Reflexão e Crítica, 21 (1), $42-50$.

Pereira, C., \& Piccinini, C. (2007). O nascimento do segundo filho e as relações familiares. Psicologia: Teoria e Pesquisa, 23 (3), 253-261.
Petean, E. B. L., \& Suguihura, A. L. M. (2005). Ter um irmão especial: convivendo com a síndrome de down. Revista Brasileira de Educação Especial, 11 (3), 445-460.

Pratta, E. M. M., \& Santos, M. A. (2007). Família e adolescência: a influência do contexto familiar no desenvolvimento psicológico de seus membros. Psicologia em Estudo, 12 (2), 247-256.

Schmidt, A. P. (2003). A Criança especial e a família. In A. M. C. Souza (Org.), A criança especial: temas médicos, educativos e sociais (pp.29-34). São Paulo: Roca.

Souza, S. C. B. \& Pires, A. A. P. (2003). Comportamento materno em situação de risco: mães de crianças com paralisia cerebral. Psicologia, Saúde \& Doença, 4 (1), 111-130.

Recebido em: 9/12/2008

Versão final reapresentada em: 19/7/2010

Aprovado em: 18/8/2010 
